\title{
UMA RESPOSTA À QUESTÃO DO ESPERANTO COMO PROPOSTA DE LÍNGUA UNIVERSAL SOB A ÓTICA DA PROBLEMÁTICA DAS IDENTIDADES.
}

\section{Dominique Vieira Coelho dos Santos}

Resumo: A partir de uma análise epistemológica das obras de Zamenhof, podemos verificar que algumas idéias linguísticas desenvolvidas por ele não se sustentam no atual contexto histórico, lingüístico e filosófico. Este é o principal argumento da crítica feita ao Esperanto. Todavia, acreditamos que uma nova leitura, feita de forma sistemática e relacional, das idéias de Zamenhof, pode conferir um novo sentido ao idioma criado por este médico polonês. Assim, este artigo pretende apresentar uma resposta à questão do Esperanto como proposta de língua universal levando em consideração a problemática das identidades.

Palavras-chave: Esperanto, identidades, língua universal.

Abstract From an epistemological analysis of Zamenhof's works, we can verify that some linguistic ideas developed by him are not supported in the current historical, linguistic and philosophical context. This is the main argument of the criticism of Esperanto. However, we believe that a new reading of Zamenhof's ideas made in a systematic and relational way can show a new meaning of the language created by this Polish doctor. Thus, this article intends to present a reply to the question of Esperanto as a proposal of a universal language taking in consideration an actual range of identity problems.

Keywords: Esperanto, identities, universal language.

Esperanto nunca foi e nunca será somente uma língua, mas um ambicioso
projeto filosófico. Fruto das reflexões do polonês Ludoviko Lazaro Zamenhof,
publicadas pela primeira vez em 1887, ele é a proposta de uma língua
internacional que auxilie a comunicação entre os mais variados povos. Por este motivo,
qualquer reflexão sobre o esperanto que pretenda abordar as aplicabilidades deste projeto
filosófico e também sua divulgação em caráter internacional não pode ignorar duas coisas: 
1) as concepções epistemológicas em que está fundamentado o pensamento de Zamenhof; 2) as implicações e as relações deste ousado projeto de língua internacional com a atual problemática da crise das identidades.

Neste artigo, são estas duas questões que nos interessam. Primeiramente, apresentamos uma tentativa de delineamento das concepções epistemológicas do criador do esperanto e, por fim, uma abordagem relacional e sistemática entre os problemas oriundos do projeto filosófico de Zamenhof tendo em vista as maneiras como pensamos as identidades hoje.

\section{1) COMPREENDENDO ZAMENHOF EPISTEMOLOGICAMENTE}

Zamenhof, um homem do século XIX. Compreender o contexto em que viveu o oftalmologista polonês tendo em vista aspectos epistemológicos é de fundamental importância para não cobrarmos de sua obra coisas que ela não poderia fornecer e também não acrescentarmos a ela signos que ainda não estavam disponíveis, comentendo anacronismos. Isto anula qualquer sugestão de que o criador do Esperanto era um homem “à frente de seu tempo”, pois, como já ressaltava o filósofo alemão Hegel, nenhum homem ou idéia está nem além e nem aquém de seu próprio tempo, mas justamente nele.

Ludoviko Lazaro Zamenhof nasceu e viveu na Polônia, quando esta era anexada ao Império Russo. Ele era filho de um professor de línguas modernas. A cidade de seu nascimento, Bialystok, era, embora pequena, palco de diversas lutas étnicas e enfrentamentos lingüísticos. Em sua cidade se falava russo, alemão, polonês e idiche. Zamenhof sabia russo, polonês e idiche, idiomas aprendidos na convivência familiar. Desde os quatro anos de idade estudava o hebraico. Aos quatorze anos, mudou-se para Varsóvia e aprendeu alemão e francês. Depois disto estudou inglês e profundamente o latim e o grego. Aprendeu também italiano e um pouco de lituano. Depois de já ter publicado seu projeto de língua internacional, Zamenhof começou a trocar correspondências com esperantistas espanhóis e também aprendeu um pouco deste idioma. Estas questões são bastante significativas porque elas acompanharão Zamenhof até o fim de sua vida. Seu objetivo foi buscar uma solução para este problema de incompreensão lingüística que ele observava desde sua infância.

Zamenhof não foi o único a pensar em uma língua internacional como tentativa de solucionar estes problemas de comunicação. Mais ou menos no mesmo período em que surgiu o Esperanto, foi criado o Volapük, por Johan Martin Schleyer, em 1880, na 
Alemanha, e uma outra língua chamada "latino sine flexione”, também conhecida como “interlíngua”, uma criação do matemático italiano Giuseppe Peano, que também ficou conhecido por ter contribuido profundamente acerca das reflexões desenvolvidas no campo da lógica, equações diferenciais e teoria dos conjuntos. O surgimento quase simultâneo destas três propostas de uma língua internacional em lugares diferentes nos leva a crer que se tratava de uma questão significativa para a época. Desta maneira, podemos perceber que Zamenhof estava ocupado com uma importante questão de seu tempo. Por isso, devemos compreender a obra do médico polonês a partir de uma análise contextual de seu pensamento tentando mapear quais eram seus sustentáculos epistemológicos. Isto será feito a partir da análise de alguns trechos selecionados de duas obras de sua autoria ${ }^{\mathrm{i}}$ relacionados com o que podemos inferir a partir de alguns sistemas epistemológicos vigentes em finais do século XIX.

O século XIX é o século das grandes enciclopédias e dicionários. É um século de crença no avanço da ciência, na racionalidade e no progresso urbano. Neste período, Paris, Londres e outras cidades européias já eram consideradas grandes metrópoles. Esta época é tida por alguns como o período de apogeu da "civilização” ocidental. É o século de Augusto Comte, de Charles Darwin, Karl Marx e também de Zamenhof. Como um pensador que viveu no fim do século XIX e primeiras décadas do XX, morrendo antes do término primeira grande guerra mundial, Zamenhof conhecia as teorias evolucionistas de Darwin, o positivismo de Comte e as grandes teorias linguísticas daquele período.

Em sua obra sobre “A essência e o futuro da idéia de uma língua internacional”, Zamenhof nos dá algumas pistas de alguns problemas destas teorias. O iniciador do Esperanto acredita que é equivocado atribuir quaisquer aspectos fisiológicos específicos dos órgãos da fala ao processo de formação de uma língua e que esta também não depende do clima ou de qualquer outro fator que pudesse fixá-la a um povo específico. Ou seja, para Zamenhof, a língua era um signo da cultura e não algo determinado geograficamente ou pela estrutura física do corpo humano, como grande parte dos estudiosos de seu tempo defendia.

Assim como outros pensadores do século XIX, Zamenhof também sustentava a crença em concepções iluministas de progresso e de conhecimento acumulativo. Desta forma, o tempo era encarado como uma continuidade e tudo quanto fosse sendo elaborado e produzido pela humanidade seria agrupado como uma espécie de saber adquirido formando uma espécie de herança. Isto é muito importante para compreendermos as idéias do iniciador do esperanto porque o projeto filosófico de uma língua internacional atendia a 
estas questões. Zamenhof acreditava que o ser humano estava em uma escala evolutiva superior aos outros animais. Em suas palavras, “estamos um degrau acima”. Esta superioridade, segundo ele, estava vinculada diretamente à linguagem. É por meio dela que poderíamos transmitir toda a produção do espírito humano já realizada.

Para Zamenhof, à medida que a Ciência avança, a humanidade faz-se mais rica em razão de novas e importantes descobertas. Seu objetivo era, portanto, colaborar com este desenvolvimento científico e aprimoramento da cultura e civilização ocidental. Ele pretendia, por meio da criação de sua língua internacional, tornar todos estes “avanços” e esta "herança" de saberes adquiridos disponível para todos. É por meio do esperanto que toda a produção do espírito humano seria acessível a todos. Zamenhof acreditava que seu trabalho seria, para a humanidade, uma "lembrança eterna”. Assim, ele inclui a si mesmo na lista dos grandes colaboradores do pensamento ocidental.

O tema do progresso está presente, de forma indiscutível no século XIX ${ }^{\mathrm{ii}}$. O projeto filosófico de Zamenhof é apenas um entre tantos outros que poderiam servir de exemplo para demonstrar este aspecto. O que Zamenhof pretendia era um aperfeiçoamento da humanidade e é aí que seu projeto apresenta certos aspectos que poderiam caracterizálo como portador de uma filosofia da história. E trata-se de uma filosofia da história de caráter otimista. Há aqui a explicação e elaboração de um sentido para a humanidade, que é o aperfeiçoamento gradual. Uma filosofia da história é justamente uma proposta de explicação do sentido da experiência humana, tendo em vista suas relações com o tempo. Significa acreditar que há na História um sentido. Claro que não temos em Zamenhof um projeto completo e acabado de uma filosofia da história. Trata-se de alguns delineamentos feitos por ele. São alguns traços que Zamenhof compartilhava com os principais sistemas epistemológicos de seu tempo.

Zamenhof acreditava que as barreiras linguísticas deveriam ser rompidas e que isto favoreceria um encontro fraterno de toda a humanidade. Por meio de suas exposições sobre a idéia de uma língua universal, podemos perceber que ele considerava um benefício para a humanidade se em um belo dia, como diz ele, se evidenciasse que já não existiam mais nações ou línguas nacionais, mas apenas uma única família humana com uma só língua. Esta utopia ficou conhecido como “a idéia interna” do Esperanto. O otimista projeto de Zamenhof tinha em vista a aproximação dos mais diversos agrupamentos humanos para uma vida em harmonia, como uma fraternidade, superando as dificuldades das guerras, as querelas religiosas, os entraves lingüísticos e as diferenças nacionais. 
Em um congresso realizado em 1906, Zamenhof chegou a dizer que seu desejo era criar um neutro fundamento, sobre o qual diversos homens pudessem, em paz e fraternidade, se comunicar. Isto seria, para ele, a queda dos muros entre os povos. Por este motivo, para ele, no reino do Esperanto reinava não somente a língua Esperanto, mas também esta interna idéia do esperantismo. Isto culminaria na criação de uma outra utopia, uma religião única para toda a humanidade, um projeto muito semelhante ao que foi elaborado por Augusto Comte. Apesar de nunca ter existido na prática, esta religião foi cuidadosamente sistematizada e publicada, em russo, por Zamenhof, sob o pseudônimo de Homo Sum, em Varsóvia no ano de 1901, com o nome de Hilelismo, recebendo, mais tarde, o nome de homaranismo. Há indícios de que ele desenvolveu estas idéias e as aperfeiçoou até o fim de sua vida. No século XX, por exemplo, Zamenhof estava tentando organizar congressos para debater a questão do homaranismo. O fundamento desta sua doutrina era: aja com os outros da mesma forma que você gostaria que agissem com você. Era uma espécie de religião do mundo, que pregava o respeito e a tolerância entre todos os credos.

Há alguns outros aspectos do projeto filosófico de Zamenhof que merecem destaque. Esta língua internacional só poderia ser uma língua neutra. Isto significa, segundo o pensamento de Zamenhof, que não poderia ser uma língua vinculada a qualquer nacionalidade. Deveria ser uma língua do mundo, uma língua da humanidade. Todavia, ele dizia que o vocabulário desta língua internacional deveria constituir-se necessariamente de palavras romano-germânicas na sua forma mais usada. Certamente, Zamenhof estava convencido de que era possível, por meio de métodos científicos, alcançar a neutralidade de qualquer coisa que seja. Esta era uma idéia bastante presente no século XIX, sobretudo, devido aos ensinamentos de Augusto Comte. O criador da língua internacional chegou a dizer, por exemplo, que a causa do Esperanto não dependia de algo pessoal ou sociedade alguma e que nenhum homem poderia ter qualquer influência sobre sua sorte porque já teria se tornado uma causa pública. Todavia, é interessante ressaltar que o vocabulário da língua internacional deveria ser constituído de palavras originadas de línguas "germânicas” e "romanas". Isto deixa claro de que, apesar de se pretender internacional, o Esperanto gira em torno de conceitos e interesses europeus, como a própria idéia do humanismo.

Zamenhof pensava a partir de alguns padrões epistemológicos baseados em dualismos comuns em sua época. Civilização e barbárie; povos esclarecidos e nãoesclarecidos são alguns exemplos. Este conceito de civilização, tal qual foi aplicado por 
Zamenhof em sua obra, implicava na existência de povos civilizados e povos selvagens. Assim, ser civilizado significava compartilhar da cultura ocidental européia. Fazia referência à noção de boas maneiras, educação, princípios morais padronizados, costumes urbanos, politização e cultura em oposição à selvageria e barbárie. Quando Zamenhof, fala, por exemplo, de suas idéias acerca do Hilelismo, ele menciona a relação que houve entre os povos considerados pagãos e os cristãos. Segundo o criador do esperanto, os pagãos aceitaram facilmente o cristianismo porque se tratava de uma religião maior e com princípios mais elaborados. Assim, quando houve o encontro do paganismo com o cristianismo, os povos pagãos, segundo Zamenhof, se viram diante de algo muito maior, que não poderiam recusar. Já o contrário não poderia ocorrer, pois, nenhuma força no mundo poderia fazer com que os cristãos se convertessem ao paganismo.

Segundo Zamenhof, o monoteísmo é a base moral de todos os homens civilizados. O hilelismo/homaranismo mantinha princípios monoteístas, por isso, segundo ele, sua religião estaria apta a integrar todos os povos que desejassem compartilhar de tal grau de civilização. Ele diz em sua obra que até mesmo o mais "primitivo africano" poderia compartilhar deste sistema religioso. É interessante aqui como Zamenhof caracteriza os povos em diferentes “níveis” ou “estágios” de civilização. Ele se refere ao africano relacionando-o com a categoria “selvagem”. “Até o mais selvagem dos africanos”. Mas, quando se refere ao europeu, caracteriza-o como "erudito". “Até o mais erudito dos europeus”. Há também uma distinção temporal, pois, em seguida, Zamenhof diz que “o mais ignorante representante dos tempos pré-históricos” poderia compreender sua doutrina. E, novamente, ele cria uma oposição ao acrescentar: “o mais erudito representante dos mais distantes tempos vindouros”, também. Podemos notar que as mesmas concepções epistemológicas estão presentes. Povos diferentes em tempos distintos. Diferentes estágios evolutivos.

Trata-se de um sistema filosófico bem semelhante ao desenvolvido por Hegel em suas lições de filosofia da história, em que podemos observar os povos com história e os povos sem história. Note-se que, como diz Zamenhof, há os representantes de tempos “pré-históricos”. Esta categoria classifica em níveis, o povo que tem "história” está em um grau de civilização maior que os que viveram em tempos “anteriores” à História. Os europeus são os civilizados, os africanos, exemplo citado por Zamenhof, são os selvagens. Assim, podemos perceber que a língua internacional, criada pelo polonês Ludoviko Lazaro Zamenhof, engloba na verdade um grande projeto filosófico de caráter humanista, com características de uma filosofia da história, completamente baseado nos princípios 
epistemológicos vigentes na Europa em finais do século XIX. Ou seja, a idéia de progresso, de sentido da História, evolução cultural, conhecimento acumulativo, neutralidade científica e a oposição entre civilização e barbárie.

\section{2) A PROBLEMÁTICA DAS IDENTIDADES}

Se o século XIX foi repleto de um otimismo científico e de crença na humanidade, na razão e na civilização, pelo menos até Nietzsche, o século seguinte já foi repleto de crises, tanto no campo dos saberes quanto nos relacionamentos entre os mais diversos agrupamentos humanos. Tivemos as duas grandes guerras mundiais, a guerra do Vietnã, a queda do muro de Berlim e diversos outros acontecimentos que marcaram o século XX como um período traumático para a história européia e do mundo em geral. No campo da ciência, presenciamos o surgimento da teoria da relatividade de Einstein, as teorias da física quântica, as novas tecnologias computacionais e, principalmente, a Internet. Foi o século do Círculo de Viena, do Estruturalismo, das análises do discurso, da Psicanálise, da Escola dos Annales e dos grandes movimentos sociais.

Houve uma profunda desconfiança na humanidade. Não foram poucos os que, como o filósofo francês Michel Foucault, principalmente em suas obras "Arqueologia do Saber" e "As palavras e as coisas”, falaram da "morte do sujeito”, da "morte do homem”, a vontade de verdade como uma vontade de poder, apontando para uma genealogia dos grandes discursos, sempre vinculados com sistemas epistêmicos, que deveriam ser analisados e compreendidos. Freud, por exemplo, escreveu sobre o mal estar da civilização e nos falou sobre a crise da razão ocidental.

Diversos movimentos chamados de “irracionalistas” surgiram. Todavia, boa parte das idéias presentes nestes movimentos, principalmente as críticas direcionadas à razão ocidental, apolínea, à crença cega na ciência, já estavam disponíveis na obra de Nietzsche, principalmente questões relacionadas com a linguagem. Enquanto a maioria dos pensadores do século XIX sustentava suas crenças na objetividade da ciência e em uma história que contasse os fatos tal qual eles ocorreram, Nietzsche já se mostrava incrédulo com relação a este otimismo do saber. Isto leva Herman Hesse, por exemplo, a dizer, de acordo com suas competências de romancista e homem da literatura, que Nietzsche já sofria por causa de problemas não compreendidos por seus contemporâneos. Nietzsche já compreendia certos aspectos filosóficos que só seriam compartilhados nas primeiras décadas do século XX, principalmente após a primeira guerra mundial. Desta maneira, 
Hesse diz que Nietzsche era um filósofo solitário, pois não tinha com quem conversar. Suas idéias ainda não eram compreendidas, principalmente sua desconfiança com relação à razão. Herman Hesse situa Nietzsche como uma espécie de lobo da estepe, relacionandoo ao personagem principal de seu mais famoso romance, que leva este nome.

Outro fator significativo foi a virada lingüística (linguistic turn), uma mudança significativa proporcionada por uma série de questões filosóficas que teve desenvolvimento no interior do campo das ciências humanas durante o século XX e que permitiu que estas levassem em conta os questionamentos acerca da narrativa, tentando, cada vez mais, superar, ou pelo menos resolver alguns aspectos, do realismo histórico e filosófico, centrado no logos, ou consciência racional, compartilhado por várias escolas e tradições historiográficas e filosóficas dos séculos XIX e início do XX. Isto gerou mudanças radicais em relação às concepções acerca do sujeito, realidade, objetividade e verdade. Desta forma, a ciência deixou de ser “um encontro com o real”. Cada vez mais, o realismo foi e vem sendo criticado. Assim, ora se postula a existência da realidade, ora se admite a existência da mesma, mas que esta é incognoscível (FALCON, 2000: p 47). Boa parte destas críticas é apresentada pelo textualismo, que acredita que, de forma alguma, o “real” pode ser apreendido. O textualismo trata a ciência, a filosofia e a história como gêneros literários e enfatiza a importância da linguagem. Para esta escola, a referência é apenas mais um entre os diversos jogos de linguagens possíveis. Assim, o que está em jogo é como as atividades humanas cognitivas e linguísticas estruturam e dão sentido ao mundo. Assim, o processo de referenciação provém de “práticas simbólicas” e não de uma “ontologia que fixa os seres em um quadro permanente” (ARAÚJO, 2004: P. 209).

Hoje, sabemos que estamos diante de códigos, sistemas de símbolos, sistemas de sentido. Trata-se de uma complexa teoria do signo, entendido como algo que representa. A representação deixa de ser entendida então como algo mimético, cópia pura e simples, para ser entendida como substituição. Ou seja, a representação não é o real. O signo é assim algo no lugar de outra coisa. Isto é uma teoria do simbolismo. Uma interpretação de fenômenos culturais. O “real” antecede qualquer pensamento humano, ou seja, o mundo já existia antes de qualquer texto ser escrito, todavia, o pensamento também configura o “real”. Só é possível referir a qualquer coisa que seja usando conceitos forjados pelo entendimento, como sabemos desde Kant, mas existe algo que não pertence ao reino dos pensamentos e que nos chega pela sensibilidade. Por este motivo, não há como abstrair o real sem o pensamento e nem o contrário. Todos estes problemas corroboraram para uma grande crise das ciências humanas e do pensamento ocidental, em geral, no século XX. 
O desenvolvimento destas idéias gerou uma crise das identidades sem precedentes. Todos os grandes sistemas explicativos dos fenômenos humanos foram abalados. O positivismo e, principalmente o marxismo, perderam seu espaço de grandes teorias reinantes. Hoje, nem um e nem outro são sistemas epistemológicos capazes de sozinhos explicarem as experiências humanas. Nosso mundo é, epistemologicamente, um mundo de aspas, um mundo plural, de vários sentidos possíveis e que deve viver em diálogo. Isto significa que as metanarrativas não têm mais o mesmo poder explicativo que tinham antes. Vivemos em um mundo de identidades fragmentadas. Isto tem provocado novos questionamentos em todos os campos do saber.

As identidades não são mais entendidas como fixas. Ao contrário, são sempre construídas mediante as representações que os grupos ou as pessoas fazem de si mesmas e dos outros. Isto significa falar de jogos de poder, principalmente o poder de configurar representações. Estas identidades só podem ser construídas, mantidas e contestadas mediante comunicação, que é sempre um processo de negociação simbólica. Assim, cultura, identidade e poder, estão imbricados e só podem ser compreendidos se forem pensados de maneira relacional e sistemática ao conceito de comunicação (MILES, 2005: p. 29-62). Pensar em identidade, hoje, significa pensar na existência de múltiplos agrupamentos humanos que existem em relação uns aos outros. As identidades são marcadas pelas diferenças, pela relação de existência com algo que está fora delas. Ou seja, a identidade precisa de uma identidade distinta dela mesma para existir. A identidade deve ser também uma “representação aceitável” (WOODWARD, 2000: P. 112). A identidade hoje é pensada sempre no plural. Não é mais possível falar de identidade, mas de identidades. Falamos de identidades étnicas, religiosas, políticas, nacionais, sexuais etc. Assim, não mais falamos apenas das grandes identidades, mas de uma completa fragmentação em grupos dentro de uma mesma sociedade. Por tudo isso, podemos dizer que a reflexão sobre a possibilidade de uma língua internacional hoje se tornou algo muito mais complexo que era no século XIX. Não é possível abordá-la sem tocar na problemática das identidades, pois qualquer reflexão que almeje apresentar discussões em níveis internacionais será obrigada a apresentar diálogos semelhantes.

A UNESCO, por exemplo, tem tentado recentemete escrever uma "HistóriaGeral da América Latina” e tem tido bastante dificuldade na realização desta tarefa por causa dos problemas relacionados com a questão das identidades. Foi criado um Comitê científico internacional para esta finalidade e o escolhido para chefiar este projeto foi um professor da Escola de História da Universidade da Venezuela chamado Germán Carreira 
Damas. Esta história da América, que já conta com nove volumes e a colaboração de mais de 240 historiadores, filósofos e especialistas das mais diversas áreas das ciências humanas e de diversas nacionalidades, vem sendo escrita já há algum tempo. O volume mais recente, o de número IX, datado de 2006, tenta analisar as principais vertentes da historiografia latino-americana ao longo do século XX. O objetivo é compreender a história desta vasta região, que é a América Latina, dando-lhe um enfoque de amplitudes globais.

As reflexões de Carrera Damas (2006) caminham no sentido de contribuir para uma renovação da consciência histórica do crioulo latino-americano e, por fim, promover o papel próprio e relativo das demais sociedades com as quais ele compartilha o território americano. O autor faz comparações internas entre estas várias populações americanas e comparações envolvendo a América Latina com outras grandes regiões geoculturais do mundo. A tese de seu texto é de que a História das sociedades latino americanas tem sido escrita e cultivada em correspondência com o processo de conformação social hegemônica do crioulo latino-americano. O crioulo latino-americano é um dominador cativo. Ele se esforça para diferenciar-se do indígena dominado, entregando-se cada vez mais ao seu cativeiro, apresentado por sua submissão a formas e padrões culturais europeus. Paradigmas que ele não elaborou, senão teve uma leve participação em sua formação. Assim sendo, esta História geral da América Latina, promovida pela UNESCO, deve, segundo Carrera Damas, ajudar a "superar”, esta visão crioula, essencialmente eurocêntrica, da História da América e contribuir para atualizar os critérios nacionais e nacionalistas que regem a historiografia latino-americana. Isto significaria escrever uma História que levasse em consideração uma revisão do modo de relacionamento das ditas sociedades que fazem parte da "História Universal” com as sociedades indígenas, com os africanos que vieram para a América e as sucessivas presenças migratórias.

As idéias apresentadas por Carrera Damas estão repletas de problemas. A maioria deles interligados com a questão da possibilidade de uma História Universal e total. Podemos perceber que ele sustenta a tese de uma unidade territorial evidente e de que a América agrupa sociedades modernas e democráticas, que apresentam uma "maturidade” sócio-cultural, podendo assim ser historicizada em sua totalidade. É justamente este o problema dos projetos universais e internacionais. Eles suplantam as identidades locais em favor de um conceito europeu de humanismo e não conseguem estabelecer um diálogo convincente, que seja capaz de se mostrar plausível perante a fragmentação das identidades. A proposta do autor é a de “reformulação” do modo de escrita da História da 
América. É uma crítica das categorias. Mas não é uma troca das categorias. Carreira Damas constrói sua narrativa baseando-se no argumento de que há a relação entre três agrupamentos sociais: europeus, crioulos e indígenas. Não é dada uma atenção mais complexa as diferenças entre indígenas e todos os aspectos culturais que existem entre eles.

O tipo de história pretendida pelo autor teria critérios nacionais e nacionalistas atualizados, seria democrática, moderna, capaz de estabelecer diálogos e de estabelecer, por este motivo, contatos com as sociedades ditas universais. Ou seja, é uma história totalmente dependente de padrões e juízos de valor europeus. A forma de se pensar a História é européia. Ainda apresenta as mesmas características comuns ao século XIX: tempo como processo, conhecimento acumulativo, integração de sociedades formando a categoria "humanidade" etc. A pretensão do autor, e não podemos esquecer que se trata de um projeto da UNESCO, de superar a visão crioula da história latino-americana, substituindo-a por uma história “autenticamente universal”, é um desejo europeu. Nunca foi intenção indígena compor uma “História Universal”. Assim sendo, este tipo de história unifica as identidades em torno dos conceitos de: nação, democracia, humanismo, racionalismo, liberalismo, criticismo e consciência histórica. Nada mais Hegeliano, nada mais europeu.

Como integrar projetos assim com as críticas levantadas pelos mais diversos pensadores ao longo do século XX, principalmente por sistemas epistemológicos ligados ao pós-colonialismo, ao feminismo, ao pós-estruturalismo e outras teorias semelhantes? Como sustentar um projeto internacional de grandes proporções, relacionando-o com identidades fragmentadas, descrença na razão, a crise do sujeito, ao processo de individualização, especialização e expansão das intenções tecnológicas? Como estabelecer critérios humanistas universais em uma época onde não se aceita mais o domínio do homem, branco, cristão, hétero, forte, esclarecido e europeu? Este problema enfrentado pela UNESCO nesta tentativa de escrita de uma "História Geral da América Latina” possui as mesmas proporções que o problema que o Esperanto enfrenta: como apresentar uma língua internacional em um tempo de crise identitária?

\section{3) ESPERANTO, LÍNGUA INTERNA OU IDÉIA INTERNA? DIVULGAÇÃo PARA ALÉM DOS MUROS DO MOVIMENTO.}

Apesar dos problemas, o esperanto funciona como língua franca. Isto já tem sido demonstrado há mais de um século de experiência lingüística, por meio de congressos, 
discussões em todas as áreas dos saberes, publicações oriundos dos mais diversos campos, programas de televisão, filmes, jornais etc. O idioma já foi recomendado como uma opção para os diálogos internacionais tanto pela ONU quanto pela UNESCO. No entanto, ao longo deste período, o esperanto também tem recebido inúmeras críticas dos mais diversos segmentos sociais. Alguns enfatizam falhas em seu alfabeto; outros apontam que o esperanto ainda não conseguiu eliminar totalmente os problemas de gênero na origem dos substantivos, que seriam todos derivados de palavras masculinas; há os que preferem enfatizar o caráter eurocêntrico do esperanto etc. Não é intenção deste artigo negar os defeitos do esperanto e os problemas que este projeto filosófico carrega consigo. Ao contrário, acredita-se que o esperanto deve assumir todos os riscos, defeitos, dilemas, problemas e fazer o que tem feito desde seu surgimento, em finais do século XIX, dialogar com todos os interessados e também com os que se opõem à tese de uma língua internacional, tentando constituir argumentação plausível. É exatamente neste ponto que percebemos o calcanhar de Aquiles do esperanto e do movimento esperantista.

A divulgação do esperanto fora dos muros do movimento esperantista precisa ser repensada, pois ela ou não existe em alcance e plausibilidade suficiente ou não consegue responder aos questionamentos apresentados pela sociedade contemporânea. Isto acontece porque falta ao movimento esperantista, principalmente no Brasil, uma integração com os principais problemas identitários de nossa época. Quando o idioma surgiu, no fim do século XIX, Zamenhof tentou de diversas maneiras responder aos anseios tanto do senso comum quanto da comunidade científica de seu tempo, algo que falta ao Esperanto hoje. Os esperantistas do século XXI precisam apresentar um diálogo mais coerente com a problemática das identidades para que ainda faça sentido falar no Esperanto como um projeto aceitável de língua internacional.

Estamos presenciando na mídia, o tempo todo, notícias falando sobre a crise dos alimentos, os diversos problemas financeiros e econômicos que assolam, principalmente os Estados Unidos, o aquecimento global, as altas, cada vez mais constantes, do preço do petróleo, a possibilidade ou não da União Européia enquanto um bloco e seus diálogos com o mundo eslavo, principalmente os países do leste europeu etc. Assistimos recentemente, problemas relacionados com a situação venezuelana nas negociações políticas latino-americanas e internacionais e seus entraves diplomáticos com a Colômbia, disputas políticas entre Brasil, Bolívia e Paraguai envolvendo recursos naturais negociados entre estes países e, por fim, a questão dos biocombustíveis. Estes são apenas alguns exemplos, praticamente todos eles de caráter político, no que diz respeito às relações 
internacionais, de alguns problemas de nosso tempo. O esperanto é capaz de se relacionar com estas questões? O movimento esperantista tem participado destes debates?

Mesmo com todos os problemas que envolviam o recém criado esperanto, uma língua ainda em caráter experimental, Zamenhof já participava dos principais debates de tendo em vista problemas étnicos, religiosos, políticos e lingüísticos. Quando lemos seu discurso acerca da essência e futuro da idéia de uma língua internacional, podemos perceber que durante toda a obra, Zamenhof está preocupado com a questão dos congressos científicos para debater o tema. Em várias passagens ele sugere a reunião de um congresso científico para estabelecimento de uma língua internacional. Quando ele fala da questão religiosa envolvendo o Hilelismo, também pensa em um grande debate para propor soluções para esta questão. Em 1901, Zamenhof já estava discutindo uma solução para a questão hebraica. Neste período, ele já falava sobre o que representaria para os judeus, ter um Estado próprio. Ele estava envolvido nos debates sobre a definição do que era nação e povo, tinha opiniões dignas de serem confrontadas com os grandes problemas lingüísticos de seu tempo etc. O movimento esperantista de nossos dias é capaz de sustentar estes projetos e debates?

A língua internacional, proposta por Zamenhof, é um projeto filosófico. Ela não é uma aquisição para sempre por parte da humanidade, que caminha rumo a igualdade e a fraternidade, como imaginava o criador do esperanto. Assim, este projeto depende, sim, de várias pessoas e sociedades. Ao contrário do que Zamenhof disse, o Esperanto não é uma língua que caminha sozinha. Ela depende de argumentação, de debate e de conflito. Tratase de um projeto filosófico que deve dar conta dos principais problemas de nossa época. Se o esperanto pretender se fortalecer e garantir sua existência para além dos muros do movimento esperantista ele deve ser capaz fornecer respostas plausíveis em diálogo com toda esta problemática das identidades fragmentadas e dos questionamentos elaborados em um mundo globalizado. Assim, chegamos a nossa principal sugestão: o Esperanto deve seguir como um projeto filosófico, tal qual Zamenhof conseguiu sustentar em debate com os principais pensadores de sua época, e não como uma língua pertencente a um movimento de caráter religioso, praticamente uma seita.

Com isto, não estamos dizendo que não deva existir esperanta movado, pasporta servo $^{\mathrm{iii}}$, congressos, encontros etc. Todavia, o movimento esperantista é que precisa ser reformulado. Só um movimento consciente de que é necessário o diálogo com as pessoas que não pertencem ao próprio grupo e que apenas enxergam estranheza nesta proposta de língua internacional será capaz de conduzir a proposta filosófica de Zamenhof para além 
dos muros do movimento esperantista. Isto significa que a proposta esperantista deve ser capaz de debater filosoficamente todas estas questões. Devemos reconhecer, em primeiro lugar, que se trata de um projeto filosófico do século XIX, baseado em todas aquelas questões que já mencionamos. Diversas pessoas que participam do movimento esperantista, principalmente no Brasil, seguem argumentando em favor do esperanto como se ainda estivéssemos no século XIX.

Estas pessoas talvez jamais tenham sequer imaginado que o esperanto traz consigo uma certa concepção identitária que é característica da Europa da época de Zamenhof. Alguns seguem ainda com este discurso da neutralidade, do humanismo, da fraternidade, da igualdade e de outros pressupostos. Isto é uma utopia, um mito cientificista. Todavia, não significa que o projeto de Zamenhof seja inválido. De fato, não o é. O Esperanto já foi testado e aprovado em todos os campos do saber. Praticamente todos os clássicos da literatura da humanidade podem ser lidos nesta língua, qualquer palavra existente pode ser expressa em esperanto, até hoje nenhum projeto de língua internacional conseguiu suplantar esta idéia, o Esperanto conta com uma literatura própria, produzida originalmente na língua e possui milhões de falantes ao redor do mundo. Então, sim! O esperanto é possível. Todavia, trata-se de um humanismo problemático, de um projeto filosófico cheio de questionamentos possíveis, de aplicabilidade questionável, de tendências eurocêntricas. É isto que o movimento esperantista precisa compreender.

Do contrário, fica parecendo que o esperanto e o movimento esperantista caminham em uma direção contrária à do mundo contemporâneo. Enquanto todos estão falando dos direitos homossexuais e da possibilidade de uma família homossexual, da questão da Amazônica pertencer ao Brasil ou ser alvo de interesses internacionais, das identidades étnicas na região basca, das questões religiosas da Irlanda, da entrada de mais países na União Européia e dos relacionamentos dos emigrantes com os europeus, das situações pós-coloniais e da luta pelas sobrevivências culturais das minorias, as dinâmicas econômicas chinesas em um período de jogos olímpicos e o que estes jogos representarão para a China, dentre tantas outras questões mais, o movimento esperantista ainda esta falando de neutralidade, de humanismo, de fraternidade, igualdade, de uma humanidade unida como se fosse uma família com uma única língua, tal qual Zamenhof, um homem do século XIX, conseguiu imaginar, mas sem estabelecer a relação com os problemas que estas teses, formuladas durante anos ao longo da história da Europa, invocam. Devemos aceitar estas questões e colocá-las em debate. Ou seja, devemos encarar os problemas filosóficos e relacionados às questões identitárias e deixar de lado os aspectos religiosos 
que podemos perceber no movimento esperantista. Aspectos religiosos que fazem o esperanto aparecer, aos olhos dos que não partilham das idéias de Zamenhof, quase que como uma seita, fechada sobre si mesmo.

\section{NOTAS DE RODAPÉ}

\footnotetext{
i Essência e futuro da idéia de uma língua internacional, publicada em 1988 e Hilelismo, datada de 1901.

ii Embora alguns autores, como é o caso de Herder, já demonstrassem, mesmo no século XVIII, certo ceticismo com relação à idéia de um aperfeiçoamento humano cumulativo.

iii Um serviço de hospedagem por meio de uma rede internacional de esperantistas distribuídos em mais de 90 países.
}

\section{REFERÊNCIAS BIBLIOGRÁFICAS}

ARAÚJO, Inês Lacerda. Do signo ao Discurso: introdução à filosofia da linguagem. São Paulo: Parábola, 2004, p. 209.

DAMAS, Germán Carrera. "Introducción General". In: Teoría y metodología en la Historia de América Latina. 1. ed. Madri: Editorial Trotta - Ediciones Unesco, 2006. v. 1. 334 p.

FALCON, Francisco J. Calazans. História e Representação. In: Representações Contribuição a um debate transdisciplinar. Campinas: Papirus, 2000, p 47.

FOUCAULT, Michel. A arqueologia do Saber. Rio de Janeiro: Forense Universitária, 2002.

. As palavras e as coisas. São Paulo: Martins Fontes, 2002.

HALL, Stuart. “Quem precisa de Identidade?”. In: Identidade e diferença: a perspectiva dos estudos culturais. Petrópolis, Vozes: 2000. P. 112.

Homo Sum. Hilelismo: projekto pri solvo de la hebrea demando. Helsink, FES: 1972

MILES, Richard. Communicating Culture, Identity and Power. In: HUSKINSON, Janet (ed.). Experiencing Rome: Culture, Identity and Power in the Roman Empire. New York: Routledge, 2005. p. 29-62.

WOODWARD, Kathryn. “Identidade e diferença: uma introdução teórica e conceitual”. In: Identidade e diferença: a perspectiva dos estudos culturais. Petrópolis, Vozes: 2000. P. 19; ZAMENHOF, Lázaro Luiz. Essência e futuro da idéia de uma língua internacional. Trad. Itacir Luchtemberg. Goiânia, Zamenhof: 1988. 